\title{
Filozofia nauki według Richarda Feynmana
}

Richard Feynman (1918-1988) uważany jest za jednego z największych fizyków teoretyków XX wieku. Najważniejszym polem jego działalności naukowej była mechanika kwantowa. Rozbudował ją znacznie przez rozwinięcie elektrodynamiki w ramach teorii kwantów. Pewne uproszczone wyjaśnienie zawiera tytuł jednego z licznych zbiorów jego wykładów, a mianowicie - elektrodynamika kwantowa to osobliwa teoria światła i materii1. Teoria ta łączy w sobie podstawy mechaniki kwantowej z elektrodynamiką i szczególną teorią względności. Początkiem badań na ten temat była praca Paula Diraca z 1927 roku2. Dirac po raz pierwszy wprowadził wówczas zasady mechaniki kwantowej do opisu pola oddziaływań3. Opracował między innymi kwantową teorię oscylatora harmonicznego. We wskazanej publikacji po raz pierwszy wprowadził pojęcie 'elektrodynamika kwantowa'.

1 Zob. R. P. Feynman, QED osobliwa teoria światta i materii, tłum. H. Białkowska, Warszawa 1992.

2 Zob. P. A. M. Dirac, The quantum theory of emission and absorption of radiation, „Proceedings of the Royal Society of London” A114 (1927), s. 243-256.

3 Paul Adrien Maurice Dirac (1902-1984) - fizyk angielski, jeden z twórców nowoczesnej mechaniki kwantowej. Wspólnie z Erwinem Schrödingerem otrzymał w roku 1933 nagrodę Nobla w dziedzinie fizyki za odkrycie nowej, efektywnej teorii atomowej. Przedstawił (1928) relatywistyczną teorię elektronu i przewidział istnienie pozytonu jako antycząstki w stosunku do elektronu. 
Kolejnym, ważnym krokiem w budowaniu nowej teorii był artykuł Wernera Heisenberga4 oraz Wolfganga Pauliego5, w którym przedstawili oni podstawy ogólnej, kwantowej teorii pola (elektrodynamika kwantowa jest jej pierwszym przykładem) i zdefiniowali jej strukturę6. Wkrótce $\mathrm{w}$ analizie elektrodynamiki kwantowej pojawiły się jednak bardzo istotne trudności i teoria musiała być znacznie zmodyfikowana. Trudności te dotyczyły w szczególności nieskończonej wartości energii w oddziaływaniu elektronu z samym sobą oraz nieskończonej ilości stopni swobody związanych z polem oddziaływań.

$\mathrm{Z}$ istnieniem tych problemów Feynman zapoznał się, będąc jeszcze studentem pierwszego stopnia w MIT (Massachusetts Institute of Technology, Cambridge, Massachusetts). Jak wspomina w swoim wykładzie noblowskim ${ }^{7}$, zainteresował się tymi zagadnieniami po lekturze książek Heitlera i Diraca ${ }^{8}$. W czasie wspomnianego wykładu zauważa między innymi: „Zainteresowały mnie uwagi, jakie znalazłem w tych książkach. Nie w tych fragmentach, gdzie wszystko było starannie opracowane, obliczone i udowodnione; w tamtym czasie nie rozumiałem ich jeszcze dobrze. Jako młody adept rozumiałem jednak uwagi o rzeczach, które wymykały się analizie. Do dzisiaj pamiętam ostatnie zdanie z książki Diraca - «Wydaje się, że potrzebne są jeszcze jakieś nowe istotne idee fizyczne.» Potraktowałem

4 Werner Heisenberg (1901-1976) - fizyk niemiecki, jeden z twórców nowoczesnej mechaniki kwantowej. Za jedno z najważniejszych osiagnięć uważa się sformułowanie zasady nieoznaczoności. W roku 1932 otrzymał Nagrodę Nobla w dziedzinie fizyki za teorię, której zastosowanie pozwoliło odkryć odmiany alotropowe wodoru.

5 Wolfgang Ernst Pauli (1900-1958) - austriacki fizyk teoretyk, laureat Nagrody Nobla w dziedzinie fizyki (1945) za sformułowanie prawa zwanego obecnie „zakazem Pauliego”. Do innych ważnych osiagnięć Pauliego należy analiza rozpadu b i przedstawienie hipotezy o istnieniu neutrina elektronowego oraz wprowadzenie tzw. macierzy Pauliego do opisu spinu elektronowego.

6 W. Heisenberg, W. Pauli, Zur Quantendynamik der Wellenfelder, „Zeitschrift für Physik“ 56 (1929), s.1-61.

7 R. P. Feynman, The Development of the Space-Time View of Quantum Electrodynamics, "Nobel lecture - Les Prix Nobel en 1965", Stockholm (1966).

8 Prawdopodobnie chodzi o książki: W. Heitler, Quantum theory of radiation, Oxford 1936 oraz P.A.M. Dirac, The Principles of Quantum Mechanics, Oxford 1930. 
je jak wyzwanie i inspirację"9. Feynman pracował nad tymi problemami wspólnie z Johnem Wheelerem ${ }^{10}$ w latach 1940-1941 oraz później, po zakończeniu wojny ${ }^{11}$. Ostatecznie znalezienie poprawnego rozwiązania zajęło mu osiem lat, aż do momentu opublikowania ostatecznego wyjaśnienia w 1948 roku. Uważa się, że istotne znaczenie dla nowego opracowania teoretycznego miały dyskusje prowadzone podczas konferencji na Shelter Island w 1947 roku $^{12}$. To nowe ujęcie opracowywali niezależnie od siebie Sin-Itiro Tomonaga ${ }^{13}$, Julian Schwinger ${ }^{14}$ oraz Richard Feynman. Za swoje prace zostali nagrodzeni Nagrodą Nobla w dziedzinie fizyki w roku 1965.

Po wojnie Feynman podjął pracę w Uniwersytecie Cornella (Cornell University, Ithaca, New York). To tu w ciagu około siedmiu lat powstały publikacje na temat elektrodynamiki kwantowej. W roku 1950 przeniósł się do Caltech (California Institute of Technology, Pasadena, California). Lata 1953-1958 Feynman poświęcił pracom dotyczącym fizyki materii skondensowanej. Tematem wiodącym były zagadnienia nadciekłości helu. W sposób odmienny od Londona ${ }^{15}$

9 R. P. Feynman, The Development of the Space-Time View of Quantum Electrodynamics, „Nobel lecture - Les Prix Nobel en 1965”, Stockholm (1966).

10 John Archibald Wheeler (1911-2008) - fizyk amerykański. Początkowo zajmował się teorią budowy jądra atomowego, w szczególności modelem kroplowym jądra. Brał udział w pracach w ramach Manhattan Project oraz w pracach nad budowa bomby wodorowej. Zajmował się też problemami ogólnej teorii względności Einsteina.

11 J. Schwinger, A Path to Quantum Electrodynamics, "Physics Today" 42 (1989), S. $42-48$.

12 F. J. Dyson, Feynman at Cornell, "Physics Today" 42 (1989), s. 32-38.

13 Sin-Itiro Tomonaga (1906-1979) - fizyk japoński. W zakresie badań dotyczących elektrodynamiki kwantowej wsławił się wprowadzeniem teorii renormalizacji. Zajmował się również wybranymi problemami z zakresu fizyki jądrowej oraz fizyki promieniowania kosmicznego.

14 Julian Schwinger (1918-1994) - fizyk amerykański. Na początku swojej kariery zainteresował się między innymi budową akceleratorów elektronów i zachowaniem się strumienia elektronów w polu magnetycznym. Te prace doprowadziły go do rozważań na temat podstawowych problemów elektrodynamiki kwantowej. Zajmował się również zagadnieniami z zakresu fizyki cząstek elementarnych.

15 Fritz Wolfgang London (1900-1954) - fizyk amerykański pochodzenia niemieckiego. Jego najważniejszym osiagnięciem były prace z zakresu teorii wiązania chemicznego i oddziaływań molekularnych (siły dyssypacyjne Londona). Zajmował się także zagadnieniami magnetyzmu nadprzewodników. 
czy Landaua ${ }^{16}$ opisał między innymi mechanizm przejścia fazowego $\lambda$ pomiędzy fazą ciekłą i stanem nadciekłości helu. Zajmował się też zjawiskiem powstawania polaronów w kryształach jonowych. Odpowiednio opracowane wyniki tych badań były treścią wykładów, jakie Feynman prowadził w Hughes Research Laboratories $(1961)^{17}$. Notatki do tych wykładów stały się podstawą do opracowania znanego podręcznika mechaniki statystycznej ${ }^{18}$. Istotne znaczenie miały również prace Feynmana o partonach. Były to jedne z pierwszych prac, które w późniejszym okresie stały się punktem wyjścia do analizy struktury wewnętrznej barionów.

Bardzo ważnym rozdziałem w życiu naukowym Feynmana był okres pracy w Los Alamos Laboratory (1943-1946), gdy wspólnie z innymi pracował pod kierunkiem Roberta Oppenheimera. Prace te były elementem dużego programu badawczego o nazwie Manhattan Project, który realizowano w latach 1942-1946. Celem badań prowadzonych przez czołowych fizyków w różnych miejscach w kraju była konstrukcja bomby atomowej. Okres ten przedstawił dość szczegółowo we wspomnieniach spisanych przez Ralpha Leightona ${ }^{19}$.

Innym znanym faktem $\mathrm{z}$ życia Feynmana jest jego udział w pracach komisji działajacej pod przewodnictwem Williama Rogersa, powołanej do wyjaśnienia katastrofy promu kosmicznego Challenger $\mathrm{w}$ roku 1986. O różnych faktach z tego okresu opowiada dość szczegółowo sam Feynman w drugiej części swoich wspomnieńn ${ }^{20}$.

16 Lew Dawidowicz Landau (1908-1968) - fizyk radziecki, laureat Nagrody Nobla w dziedzinie fizyki (1962). Nagrodę otrzymał za fundamentalny wkład w rozwój fizyki fazy skondensowanej, w tym za teorię dotyczącą ciekłego helu.

17 D. Pines, Richard Feynman and condensed matter physics, "Physics Today" 42 (1989), s. 61-66.

18 Zob. R. P. Feynman, Wyktady z mechaniki statystycznej, tłum. K. Makowski, Warszawa 1980.

19 R. P. Feynman, Pan raczy żartować, Panie Feynman!, tłum. T. Bieroń, Kraków 1996.

20 R. P. Feynman, A co ciebie obchodzi, co myśla inni?, tłum. R. Śmietana, Kraków 1997. 


\section{Odrzucenie filozofii}

Feynmanowi przypisuje się następująca opinię (Trubody, 2016): filozofia nauki jest tak samo przydatna dla uczonych, jak ornitologia dla ptaków. Jest to przykład wypowiedzi, które mają świadczyć o jego niechęci do filozofii. Bardzo krytyczne uwagi na temat filozofów znajdujemy na przykład w Wykładach Feynmana ${ }^{21}$. Tu pojawia się określenie „kawiarniani filozofowie”, którym Feynman przypisuje domniemane wypowiedzi na temat względności ruchu świadczące o braku zrozumienia problemu: „Och! To bardzo proste: teoria Einsteina powiada, że wszystko jest względne” albo „Konsekwencją odkryć Einsteina jest względność wszystkiego; ma to głęboki wpływ na cała myśl ludzka" ${ }^{22}$. W dalszej części krytyka jest jeszcze ostrzejsza, gdy Feynman przypisuje filozofom wypowiedź na temat prędkości bezwzględnej: „To oczywiste, że nie można zmierzyć bezwzględnej prędkości bez wyglądania na zewnątrz. Nie ma w ogóle sensu mówić o prędkości czegoś bez wyglądania na zewnątrz. To, że fizycy myśleli, iż jest inaczej, świadczy, że są oni dość głupi, ale teraz zaświtało im w głowach i wiedza już, jak jest naprawdę. Gdybyśmy tylko my, filozofowie, zdawali sobie byli sprawę z trudności, jakie mają fizycy, moglibyśmy momentalnie, przy pomocy samego tylko wysiłku umysłowego, dojść do stwierdzenia, że niepodobna ocenić własnej prędkości bez wyjrzenia na zewnatrz" ${ }^{23}$. W podsumowaniu tych rozważań Feynman spieszy z wyjaśnieniem, że „[...] o tym, czy coś jest mierzalne, nie można zdecydować a priori przy pomocy samego rozumowania, lecz trzeba to rozstrzygnąc przy pomocy doświadczenia" ${ }^{24}$.

21 R. P. Feynman, R. B. Leighton, M. Sands, Feynmana wyktady z fizyki, t. 1.1, tłum. R. Gajewski, Warszawa 2007.

${ }^{22}$ R. P. Feynman, R. B. Leighton, M. Sands, Feynmana wyktady z fizyki, dz. cyt., s. 243 .

${ }^{23}$ R. P. Feynman, R. B. Leighton, M. Sands, Feynmana wykłady z fizyki, dz. cyt., s. 244 .

${ }^{24}$ R. P. Feynman, R. B. Leighton, M. Sands, Feynmana wyktady z fizyki, dz. cyt., s. 244 . 
Podstawowym zarzutem kierowanym przez Feynmana wobec filozofii jest jej nadmierna dbałość o definicje i pojęcia, które przedstawiciele tej dziedziny nauki potrafią rozważać i analizować w nieskończoność. Sam natomiast uważa, że „Przyroda nie przywiązuje wagi do naszych nazw, po prostu działa" ${ }^{25}$. Feynman stwierdza, że pojęcia i definicje są bardzo potrzebne w nauce, ale to nie jest nauka, to sa jedynie narzędzia nauki- ,ważne jest, by dostrzec różnicę oraz by wiedzieć, kiedy uczymy tylko o narzędziach, którymi posługuje się nauka, takich jak słowa, a kiedy przekazujemy samą naukę"26. Jako przykład takiego myślenia można zacytować uwagi Feynmana dotyczące nazw związków chemicznych: „,...] nazwa ma nie tylko odzwierciedlać kształt czasteczki. Ale również informować, że tu jest atom tlenu, a tam wodoru - dokładnie co i gdzie"27.

Ben Trubody stawia jednak tezę, że Feynman może być uważany za niedocenionego i niezauważonego filozofa nauki ${ }^{28}$. Na początek Trubody rozważa podstawowe zadania nauki, które w tradycyjnym ujęciu prowadzą do stwierdzenia, że nauka to rodzaj metodologii poznawania przyrody. Rozpoczyna od stwierdzenia, że zadaniem nauki jest ocena hipotez na podstawie obserwacji. Na podstawie analizy wielu wypowiedzi Feynmana można zauważyć, że w jego opinii jest to jednak tylko sposób mówienia o nauce jako takiej, tak jak ornitologia jest metodą mówienia o ptakach. Jest też inny model, oparty na indukcji, który wywodzi się z filozofii Francisa Bacona. Na podstawie pojedynczych obserwacji formułowane sa, drogą indukcji, prawa ogólne. Takie podejście jest również krytykowane przez Feynmana. Nie można prowadzić obserwacji w sposób chaotyczny. Trzeba umieć podejmować decyzję, co ma być obserwowane.

${ }^{25}$ R. P. Feynman, R. B. Leighton, M. Sands, Feynmana wykłady z fizyki, dz. cyt., s. 28 .

26 R. P. Feynman, The Pleasure of Finding Things Out, Cambridge, Massachusetts 1999 , s. 178.

${ }^{27}$ R. P. Feynman, R. B. Leighton, M. Sands, Feynmana wyktady z fizyki, dz. cyt., s. 31 .

28 B. Trubody, Richard Feynman's Philosophy of Science, "Philosophy Now" 114 (2016). 
We wstępie do swoich słynnych Wykładów Feynman stawia tezę: „U podstaw wszystkich nauk przyrodniczych leży zasada, którą można nieledwie uważać za ich definicję: sprawdzianem wszelkiej wiedzy jest doświadczenie. Doświadczenie jest jedyną miarą "prawdy» naukowej. Ale co jest źródłem samej wiedzy? Skąd się biorą prawa, które doświadczenie ma potwierdzić? Doświadczenie pomaga nam je odkrywać, w tym sensie, że daje wskazówki, naprowadza nas na właściwą drogę. Ale konieczna jest też wyobraźnia, która, opierając się na tych wskazówkach, tworzy śmiałe uogólnienia i potrafi odgadnąc wspaniała, przedziwną a jednocześnie prostą regularność ukrytą w faktach, a następnie zaplanować doświadczenia sprawdzające, czy dobrze odgadliśmy" ${ }^{29}$. Jest to pogląd zbliżony do stanowiska Mariana Smoluchowskiego ${ }^{30}$, który określił takie działanie w nauce mianem „romantyzmu naukowego" ${ }^{31}$. Dla Smoluchowskiego była to postawa przeciwna do stanowiska pozytywistów, którzy odrzucali wszelkie spekulacje i uważali doświadczenie za jedyne źródło wiedzy. Pogląd Feynmana zawiera zatem pewne sprzeczności. Może należy uznać, że stanowisko Feynmana jest bliższe poglądom współczesnego mu fizyka teoretyka Carla Friedricha von Weizsäckera $^{32}$, który podkreślał zawsze znaczenie doświadczenia fizycznego, jako niezbywalnej podstawy wszelkiej wiedzy fizycznej. Podkreślał jednak znaczenie również rozważań teoretycznych w fizyce, przyjmując, że „w rzeczywistości doświadczenie jest ślepe, jeżeli nie jest podyktowane przez myśl teoretyczną albo przynajmniej przez tę myśl s. 20 .

${ }_{29}$ R. P. Feynman, R. B. Leighton, M. Sands, Feynmana wyktady z fizyki, dz. cyt.,

30 Marian Smoluchowski (1872-1917) - polski fizyk eksperymentator i teoretyk. Za jego najważniejsze osiagnięcie uważa się, niezależną od opracowania Einsteina, teorię wyjaśniająca ruchy Browna. Gorący orędownik atomizmu w czasach, gdy bardzo duże znaczenie w naukach przyrodniczych miały poglądy pozytywistów.

31 M. Smoluchowski, Dzisiejszy stan teorii atomistycznej, w: Wybór pism filozoficznych, red. W. Krajewski, Warszawa 1956.

${ }^{32}$ Carl Friedrich von Weizsäcker(1912-2007) - niemiecki fizyk i filozof. Artykuły opublikowane przed II Wojną Światową dotyczą głównie fizyki jądra atomowego. Do największych osiagnięć należy zaliczyć prace na temat masy jądra atomowego oraz odkrycie tzw. cyklu węglowego. Po wojnie Carl Friedrich von Weizsäcker poświęcił się w dużej mierze filozofii nauki. Zajmował się również zagadnieniami z pogranicza fizyki i religii, a w roku 1989 został laureatem Nagrody Templetona. 
tłumaczone. Narzędziem myślenia w fizyce jest matematyka, ponieważ fizyka bada związki pomiędzy wielkościami, które mierzymy, a więc wyrażamy liczbami. Stąd obok fizyki doświadczalnej mamy fizykę teoretyczna, czyli matematykę" ${ }^{33}$. Bardziej precyzyjnie Weizsäcker definiuje swoje poglądy w tym względzie w innej pracy, opisujac proces tworzenia teorii naukowej w fizyce:,[...] fizyka rozwija się od jedności przez wielość znowu do jedności. Pojęcie jedności jest przy tym inaczej rozumiane na początku niż na końcu. Na początku jest jedność koncepcji. Potem następuje wielość doświadczeń. Zrozumienie ich zawdzięczamy właśnie tej początkowej koncepcji. Ona to dopiero umożliwia planową działalność eksperymentalną. Nowe zrozumienie uzyskane z kolei dzięki doświadczeniom działa niejako wstecz, modyfikujac pierwotna koncepcję. W ten sposób dochodzi do jej załamania; w tej fazie jedność wydaje się całkowicie zagubiona. Ale na końcu powraca i utrwala się jedność nowej koncepcji panującej we wszystkich szczegółach nad wielością uzyskanych już doświadczeń. To nazywają w fizyce teorią w poważnym sensie tego słowa"34. W swoich wypowiedziach na temat relacji pomiędzy doświadczeniem a teorią Feynman nie jest niestety aż tak precyzyjny.

\section{Czym jest nauka?}

Z relacji innych wiadomo, że Feynman miał dość szczególne podejście do nauki. David Louis Goodstein twierdzi, że Feynman, jako miłośnik wszelkich zagadek i gier, patrzył na świat przyrody jak na swego rodzaju grę, w której obowiąują określone reguły, jedne znane, inne nieznane $^{35}$. Goodstein stara się wyjaśnić to podejście, pisząc dalej: „Mając do dyspozycji «znane» reguły, odkryj istotę procesu, mając do dyspozycji wiedzę o procesie - znajdź reguły. Poszukaj miejsc

${ }^{33}$ C. F. von Weizsäcker, J. Juilfs Fizyka współczesna, tłum. W. Staszewski, A. Teske, Warszawa 1963, s. 13.

34 C. F. von Weizsäcker, Jedność przyrody, tłum. K. Napiórkowski, J. Prokopiuk, H. Tomasik, K. Wolicki, Warszawa 1978, s. 241-242.

35 D. L. Goodstein, Richard P. Feynman, teacher, „Physics Today” 42 (1989), s. $70-75$. 
i okoliczności, w których znane reguły nie działają i znajdź nowe, odpowiednie" 36 .

W kwietniu 1966 roku Feynman wystapił podczas dorocznego zjazdu Krajowego Stowarzyszenia Nauczycieli Przedmiotów Przyrodniczych ${ }^{37}$. Poproszono go o przedstawienie problemu zamkniętego w pytaniu: Czym jest nauka? W swoim komentarzu do rozważań Feynmana na temat nauki Trubody stwierdza krótko, iż według Feynmana nauka jest tym, co robia naukowcy - formułuja hipotezy, które poddaja weryfikacji przez obserwacje ${ }^{38}$. Uzasadnienie dla takiego podejścia podaje Feynman, wspominając swoje pierwsze kroki w poznawaniu przyrody poczynione pod kierunkiem swojego ojca. Ważne były wówczas obserwacje, a nie pojęcia. Zaznacza przy tym, że niezwykle istotne, by nauczając innych jak prowadzić obserwacje, pokazać jednocześnie, iż mogą one przynieść wspaniałe wyjątkowe przeżycie. Jest to unikalna nagroda ogromnej wartości, którą otrzymuje tylko cierpliwy obserwator.

Przykładem bardzo dobrze ilustrujacym to zagadnienie jest wypowiedź Feynmana w jednym z wywiadów udzielonych telewizji BBC, dotycząca zachwytu nad pięknem przyrody. W tym przypadku chodzi o kwiat. Jak opowiadał Feynman, pewien artysta starał się zwrócić jego uwagę, mówiąc: „Popatrz, widzisz jaki piękny jest ten kwiat. Ja, jako artysta, potrafię dostrzec jego piękno, Ty, jako naukowiec, zaczniesz rozkładać go na części pierwsze i stanie się on nudny"39. Feynman, komentując tę uwagę stwierdza, że również potrafi docenić tego rodzaju piękno, tak jak potrafią to również wszyscy inni. Jako naukowiec potrafi jednak zauważyć inny rodzaj piękna - bogactwo i złożoność wewnętrznej struktury kwiatu. Zastanowienie nad pięknem wewnętrznym rodzi bardzo dużo interesujących problemów. Wiedza naukowa zatem wzbogaca ten szczególny rodzaj tajemnicy i zachwytu, nie ujmując nic z powszechnie dostrzeganego piękna. Jak

36 D. L. Goodstein, Richard P. Feynman, teacher, „Physics Today” 42 (1989), s. $70-75$.

${ }_{37}$ R. P. Feynman, What is Science, „The Physics Teacher” 7 (1969) no. 6, s. $313-320$.

38 B. Trubody, Richard Feynman's Philosophy of Science, dz. cyt.

${ }_{39}$ R. P. Feynman, The Pleasure of Finding Things Out, dz. cyt., s. 2. 
podkreśla dalej: „wiedza naukowa [...] tylko dodaje. Nie rozumiem jak mogłaby odejmować" 40 .

W swoich rozważaniach o tym czym jest nauka Feynman podkreśla jednak, że obserwacje prowadzone przez jedną osobę są z definicji czasstkowe i mają wartość jedynie dla niej samej. Co innego, gdy wyniki obserwacji są przekazywane innym, tworząc w ten sposób ogromny zasób wiedzy, jakim dzisiaj dysponujemy. Problem w tym, że nie wszystkie obserwacje sa poprawnie interpretowane, a wyprowadzone wnioski mogą być fałszywe. Niezwykle ważna jest wówczas zdolność do rozważnego rozpoznania i odrzucania tez fałszywych i do przyjęcia tez poprawnych. Właśnie w tym momencie Feynman dochodzi do odpowiedzi na pytanie czym jest nauka. Stwierdza bowiem: „To jest powątpiewanie, czy przekaz wcześniejszy jest rzeczywiście prawdziwy, to próba ponownego odkrywania ab initio, przez doświadczenie, jaki jest stan rzeczywisty. Jest to ważniejsze niż zaufanie do przekazu poprzedników zapisane w starodawnej formie" ${ }^{41}$. W ten sposób definiuje ostatecznie to, co nazywa nauką.

Feynman przypisuje nauce istotne według niego atrybuty, do których zalicza wolność myślenia. Najważniejszą sprawa jest w tym przypadku umiejętność wyzwolenia się od wpływu innych, zwykle wcześniejszych poglądów i twierdzeń. Taką właśnie niezależność intelektualną i pewien rodzaj mądrej odwagi uważa Feynman za istotę nauki.

\section{Wartość nauki}

Poszukiwanie odpowiedzi na pytanie Czym jest nauka? warto uzupełnić rozważaniami o wartości nauki. Feynman stawia sobie tym razem zadanie, by poszukać uzasadnienia dla swojej własnej pracy wobec faktu, iż przyczynił się do konstrukcji bomby atomowej. Stawia sobie pytanie: „Jaką wartość ma nauka, której się poświęciłem,

40 R. P. Feynman, The Pleasure of Finding Things Out, dz. cyt., s. 2.

41 R. P. Feynman, The Pleasure of Finding Things Out, dz. cyt., s. 185. 
która kocham, wobec tych wszystkich okropieństw, jakie potrafi stworzyć?"42.

Punktem wyjścia w tych rozważaniach jest buddyjskie przysłowie: „Każdy człowiek jest obdarzony kluczem, który otwiera bramy niebios, ale ten sam klucz otwiera też bramy piekieł" ${ }^{\prime 3}$. Należy rozumieć, że dla Feynmana takim kluczem jest nauka. Jej wartość, jak sam podkreśla, w pierwszym rzędzie polega na tym, iż umożliwia nam robienie wszystkiego i wytwarzanie wszystkiego. Daje nam zatem moc do czynienia dobra i zła. Jednak nie niesie z sobą instrukcji, jak czynić dobro.

Jedną z ważniejszych cech nauki, która decyduje o jej wartości jest dla Feynmana fakt, iż niesie ona z sobą satysfakcję intelektualną. Jak pisze; ,[satysfakcję tę - G.Ś.] niektórzy ludzie czerpia z czytania, uczenia się lub myślenia o niej, a inni z pracy [naukowej - G.Ś.']"44. Szybko dodaje też, że równie ważny jest nasz sposób patrzenia na świat uzyskany dzięki wiedzy naukowej. Dzięki nauce ogląd natury, wyobrażenie o jej bogactwie jest milion razy większe, niż wyobraźnia artystów. Sens tego twierdzenia starał się pokazać we wspomnianej wcześniej krótkiej anegdocie na temat piękna kwiatu.

W rozważaniach nad wartością nauki warto przytoczyć uwagi przedstawione przez Feynmana w jednym z przemówień wygłoszonych w Caltech (1974). Było to wystapienie podczas uroczystości wręczania dyplomów absolwentom tej uczelni. Nadano mu tytuł Nauka na wzór kultu cargo (Cargo cult science) ${ }^{45}$. Pojęcie kultu cargo w odniesieniu do działalności naukowej wymyślił sam Feynman. Uzasadnił je przedstawiając krótką przypowieść o ludziach z wysp na Morzach Południowych. W czasie wojny lądowały tam samoloty dostarczające cenne dla tubylców towary. Kiedy transporty ustały, sami przygotowali kolejne lądowisko, ustawili drewnianą budkę jako

${ }^{42}$ R. P. Feynman, The Pleasure of Finding Things Out, dz. cyt., s. 141.

43 R. P. Feynman, The Pleasure of Finding Things Out, dz. cyt., s. 142.

44 R. P. Feynman, The Pleasure of Finding Things Out, dz. cyt., s. 143.

45 Tekst opublikowany pierwotnie w czasopiśmie lokalnym uczelni Caltech „Engineering \& Science” - odtworzony, jak wiele innych, na podstawie zapisu audio tego wystapienia. 
wieżę kontrolną i umieścili w niej ludzi z drewnianymi słuchawkami na uszach, a pędy bambusowe służyły jako anteny, ale samoloty jednak się nie pojawiały. W ten sposób Feynman ilustruje pewien rodzaj „pracy naukowej”, gdy sa ludzie gotowi do pracy w bardzo dobrze wyposażonych laboratoriach, w bogatych bibliotekach, ale wartościowych wyników naukowych brak. Dlaczego? Bo w tej „pracy naukowej” brak idei. Feynman wyjaśnia dalej sens tej idei: „Jest to ta cecha ogólna nauki, podstawa myśli naukowej, która odpowiada bezwzględnej uczciwości, całkowitemu oddaniu sprawie"46.

W przypadku prowadzenia doświadczeń problem uczciwości naukowej wydaje się prosty w swej istocie, ale trudny w realizacji. Nie chodzi tu tylko o niefałszowanie wyników, ale przede wszystkim o ich rzetelną analizę, o precyzyjną kontrolę warunków prowadzenia eksperymentu oraz o precyzyjny opis matematyczny. Czasem bowiem, gdy przewidywania teorii tylko „trochę” odbiegaja od wyników doświadczenia, to głęboka analiza może doprowadzić do całkowitego odrzucenia proponowanego wyjaśnienia teoretycznego.

Feynman rozwija myśl o uczciwości naukowej, nie ograniczając jej jedynie do prowadzenia doświadczeń. W przypadku teorii, przy okazji jej publikacji, należy podać wszystkie argumenty, wszystkie te fakty, które przemawiają za jej słusznościa, i te, do których ona nie pasuje. Działanie sprzeczne z tą zasada, prowadzone świadomie, jest przykładem nieuczciwości naukowej, a prowadzone nieświadomie - przykładem oszukiwania samego siebie.

Problem uczciwości naukowej wiąże się tė̇ z uzależnieniem naukowców od finansowania ich pracy. W prowadzeniu badań potrzebne są niekiedy powtórzenia uznanych już wcześniej doświadczeń, przeprowadzenie tych samych badań w różnych warunkach i optymalizacja tych procesów. Odmowa finansowania tego typu działania ze względu na „oszczędne” i „racjonalne” gospodarowanie jest tu bardzo częstym i dobitnym przykładem. Dla Feynmana takie postępowanie jest sprzeczne z tym, co stanowi o istocie nauki.

Czy te rozważania, bardzo ważne, zawierają w sobie, w zamyśle autora, pewną myśl filozoficzną? Chyba nie. Sa to uwagi czysto

${ }^{46}$ R. P. Feynman, The Pleasure of Finding Things Out, dz. cyt., s. 209. 
praktyczne, nieocenione i ważne, ale takie, które każdy może zrozumieć jedynie w trakcie własnych zmagań z wyjaśnieniem zjawisk przyrodniczych. Myśl filozoficzna, nawet najbardziej dogłębna, nie jest w stanie zastapić tego osobistego doświadczenia.

Najważniejszą jednak sprawa, która dla Feynmana wiąże się z wartością nauki, jest prawo do stawiania pytań, do zgłaszania wattpliwości. W swojej pracy uczony ma często do czynienia z głupota, ale też z powątpiewaniem i niepewnościa. Ogromne znaczenie dla uzyskania jakiegokolwiek postępu ma jego zdolność do rozpoznawania głupoty i zachowania pewnej przestrzeni dla niepewności i powątpiewania. Jak pisze: „Wiedza naukowa jest zbiorem twierdzeń o zróżnicowanym stopniu pewności - niektóre mocno niepewne, inne prawie pewne, ale żadne nie jest absolutnie pewne" ${ }^{47}$. Przez wieki udało się uczonym wywalczyć prawo do powątpiewania w prawa odkryte wcześniej przez innych. Były to ogromnie trudne zmagania $\mathrm{z}$ autorytetem $\mathrm{w}$ nauce $\mathrm{i}$ bardzo ważne jest, by tych zdobyczy nie stracić. W tym upatruje Feynman między innymi odpowiedzialność nauki wobec społeczeństwa.

\section{Podsumowanie}

Wielu fizyków stara się, w oparciu o swoją wiedzę fachowa, przedstawiać różne zagadnienia w ujęciu bardzo ogólnym, wysnuwać wnioski zarówno w odniesieniu do filozofii nauki, jak i w odniesieniu do ważnych problemów filozoficznych. Powstają na przykład wnikliwe opracowania z zakresu kosmologii, czy fizyki cząstek elementarnych, które kończą się zwykle ogólnymi stwierdzeniami na temat ewolucji i struktury Wszechświata. Są jednak fizycy, którzy nie poświęcaja tym zagadnieniom osobnych publikacji. Trzeba wówczas prowadzić szczegółową analizę wybranych dzieł, by na tej podstawie zdefiniować ich poglądy, czy postawy filozoficzne. Do takich uczonych należał zapewne Richard Feynman. Dla niego najważniejszym pytaniem natury ogólnej było - czym jest nauka i jaka jest jej wartość? Odpowiedzi,

${ }^{47}$ R. P. Feynman, The Pleasure of Finding Things Out, dz. cyt., s. 146. 
jakich udzielał sobie i innym wynikały z jego doświadczeń w pracy dydaktycznej, z jego rozmów z Ojcem, z jego rozważań o osobistej odpowiedzialności za konstrukcję bomby atomowej. Te odpowiedzi wydają się proste, zdroworozsądkowe, może zbyt powszechne. Charakteryzują się jednak swoistą głębią osobistych przeżyć, zaangażowaniem emocjonalnym i poczuciem obowiązku upowszechniania wartościowej wiedzy o otaczającym nas świecie przyrody. Tym co podkreślał szczególnie, jako wartość nauki, było poczucie niezależności wobec autorytetów i wobec zastanej wiedzy. Była to również odwaga w ocenie tychże autorytetów. Odwaga do tego, by istniejące tezy weryfikować samodzielnie, wychodząc od praw podstawowych.

\section{Summary}

\section{Philosophy of Science by Richard Feynman}

Richard Feynman, one of the greatest physicists became famous for his discoveries concerning quantum electrodynamics and for his lectures. His views on science appear to be very simple, common-sense, but they present the essence of the problem. What he values in science the most is the freedom of thinking and a sort of reasonable courage, which enable one to oppose earlier authorities. When it comes to education, the most important is to teach the ability to observe the nature around.

Keywords: essence of science, value of science, Richard P. Feynman.

\section{Bibliografia}

Dirac P. A. M., The quantum theory of emission and absorption of radiation, „Proceedings of the Royal Society of London” (1927) A114, s. 243-256.

Dyson F. J., Feynman at Cornell, „Physics Today” 42 (1989), s. 32-38.

Feynman R. P., A co ciebie obchodzi, co myśla inni?, tłum. R. Śmietana, Kraków 1997.

Feynman R. P., Leighton R. B., Sands M., Feynmana wykłady z fizyki, t. 1.1, tłum. R. Gajewski, Warszawa 2007.

Feynman R. P., Pan raczy żartować, Panie Feynman!, tłum. T. Bieroń, Kraków 1996. 
Feynman R. P., QED osobliwa teoria światła $i$ materii, tłum. H. Białkowska, Warszawa 1992.

Feynman R. P., The Development of the Space-Time View of Quantum Electrodynamics, „Nobel lecture - Les Prix Nobel en 1965”, Stockholm (1966).

Feynman R. P., The Pleasure of Finding Things Out, Cambridge, Massachusetts 1999.

Feynman R. P., What is Science, „The Physics Teacher” 7 (1969) no. 6, s 313 320.

Feynman R. P., Wykłady z mechaniki statystycznej, tłum. K. Makowski, Warszawa 1980.

Goodstein D. L., Richard P. Feynman, teacher, „Physics Today” 42 (1989), s. $70-75$.

Heisenberg W., Pauli W., Zur Quantendynamik der Wellenfelder, „Zeitschrift für Physik“ 56 (1929), s.1 - 61.

Pines D., Richard Feynman and condensed matter physics, „Physics Today” 42 (1989), s. 61-66.

Schwinger J., A Path to Quantum Electrodynamics, „Physics Today” 42 (1989), s. $42-48$.

Smoluchowski M., Dzisiejszy stan teorii atomistycznej, w: Wybór pism filozoficznych, red. W. Krajewski, Warszawa 1956

Trubody B., Richard Feynman's Philosophy of Science, „Philosophy Now” 114 (2016).

von Weizsäcker C. F., Juilfs J., Fizyka współczesna, tłum. W. Staszewski, A. Teske, Warszawa 1963.

von Weizsäcker C. F., Jedność przyrody, tłum. K. Napiórkowski, J. Prokopiuk, H. Tomasik, K. Wolicki, Warszawa 1978. 